\title{
A Consumer Perception Study on Functional Dairy Products Among Consumers in Istanbul, Turkey
}

\begin{tabular}{|c|c|}
\hline \multicolumn{2}{|c|}{$\begin{array}{l}\text { Sanem Argın }{ }^{1, a, *} \text {, Belin Eskinazi }{ }^{\mathbf{1 , b}} \text {, Didem Tavlı }{ }^{\mathbf{1 , c}} \\
{ }^{1} \text { Department of Food Engineering, Faculty of Engineering, Yeditepe University, } 34755 \text { Istanbul, Turkey } \\
{ }^{*} \text { Corresponding author }\end{array}$} \\
\hline A R T I C LE I NFO & A B S T R A C T \\
\hline $\begin{array}{l}\text { Keywords: } \\
\text { Functional dairy } \\
\text { Consumer perception } \\
\text { CATA } \\
\text { Health claim } \\
\text { Willingness to purchase }\end{array}$ & $\begin{array}{l}\text { The aim of this study is to understand Turkish consumers' perception of functional dairy products } \\
\text { in three different categories, namely milk, yogurt, and cream cheese, as well as their willingness to } \\
\text { buy products with health claims. In this study, } 50 \text { untrained participants from the city of İstanbul, } \\
\text { Turkey, were enrolled to evaluate three types of milk (calcium \& vitamin fortified, soy, and whole), } \\
\text { three types of yogurt (probiotic, strawberry flavoured probiotic, and plain) and four types of cream } \\
\text { cheese (calcium, phosphate \& vitamin fortified, reduced fat, light, and regular) using free listing } \\
\text { testing and check-all-that-apply (CATA) questions together with Yes/No questions. Twenty-five } \\
\text { participants were recruited from Yeditepe University's Food Engineering Department and } 25 \\
\text { participants from public places to form two clusters. In the free listing analysis, the number of } \\
\text { frequent terms related to health dramatically decreased after the tasting session for all products, } \\
\text { whereas sensory related terms became more important. CATA analysis showed that consumers look } \\
\text { for different product properties in different dairy categories. The findings of both analyses showed } \\
\text { that, regardless of their education and awareness, consumers still are not willing to compromise on } \\
\text { the taste of dairy foods independent of how healthy the product might be. Their preference of } \\
\text { functional dairy products was only } 22 \%, 26 \% \text { and } 14 \% \text { for fortified milk, probiotic yogurt, and } \\
\text { fortified cream cheese, respectively. Moreover, only } 30 \% \text { of the participants were found to believe } \\
\text { the health claims on the package, which is another obstacle the functional food industry has to face. }\end{array}$ \\
\hline
\end{tabular}

\section{Introduction}

Food choice is a complex consumer behavior in which many factors are involved (Shepherd, 1999; Grunert et al., 2000; Lindeman and Sirelius, 2001; Fenko et al., 2016). To date, health and weight control have become trendy and crucial in influencing the purchasing behavior of consumers (Johansen et al, 2011). Consumer's awareness of the relationship between food and health, as well as food and diseases such as high blood pressure, cholesterol, obesity, cancer, and cardiovascular problems, is one of the underlying reasons why the market share of functional foods continues to increase worldwide. Foods with functional claims can be found almost in all categories (Siro et al., 2008). Nevertheless, while consumers appear to recognize the role of food in preserving health, inherent challenges remain in terms of consumer acceptance and perception of functional foods (Urala and Lähteenmäki, 2007; Menezes et al., 2011; Ozen et al., 2012; Özen et al.,
2014; Büyükkaragöz et al., 2014). For instance, consumers do not want to compromise the taste of food for health (Verbeke, 2006), while some simply just do not believe in the health claims on the products (Kaur and Singh, 2017). Specifically, it has been reported that factors such as gender, age, education, psychological factors, productrelated characteristics, culture, traditions, eating habits, price, brand, presence of children in the household, neophobia and even packaging features all play a role in the purchasing behavior of functional foods (Bower et al., 2003; Coxa et al., 2004; Verbeke, 2006; Ares and Gambaro, 2007; Ares et al., 2010a; Ares et al., 2010b; Johansen et al., 2010; Nocella and Kennedy, 2012; Carillo et al., 2013; Bornkessel et al., 2014; Gulseven and Wohlgenant, 2014; Pappalardo and Lusk, 2016; Bimbo et al., 2017; Kaur and Singh, 2017; Pinto et al., 2017). 
Moreover, studies have shown that how consumers perceive the health benefit varies with the carrier, namely the type of product that contains the functional ingredient (Krutulyte et al., 2011; Nocella and Kennedy, 2012). Internationally, dairy products are considered as the most preferable carrier for functional ingredients (Krutulyte et al., 2008; Siegrist et al., 2008; Annunzita and Vecchio, 2013), amongst which yogurt is the most studied vehicle to incorporate bioactive ingredients, followed by milk, cheese and milk desserts (Bimbo, 2017). Examples of healthrelated modifications of dairy products include addition of probiotics, omega-3, antioxidants, fiber, calcium, vitamins, and iron besides providing a low-fat alternative (Bimbo, 2017). Similarly, functional dairy products also lead the Turkish functional food market, although their production volume is still below the global figures (Karagözlü, 2015). To develop and market new functional dairy products Turkish companies must have a clear understanding of the consumers' perception and their motives toward purchasing functional products.

In the present study, we aimed to understand the consumers' perception of functional dairy products in three different categories (milk, yogurt and cream cheese), as well as their willingness to buy products with health claims. The results of this study should provide insights for the Turkish dairy manufacturers and the functional food producers in general.

\section{Materials and Methods}

\section{Recruitment of Participants}

For each product group investigated in the study 50 untrained participants at ages between 18 and 65 years were employed (Cruz et al., 2013). Participants who consumed milk, cheese, and yogurt at least once a week were selected randomly. Twenty-five participants were recruited from the Food Engineering Department of Yeditepe University (students and faculty members) and another 25 were recruited from the public to form two clusters. Cluster analysis was performed to divide the observations into homogeneous and distinct groups. Sessions were conducted on separate days with respective groups of participants recruited for different product categories (overall 116 different participants). The majority of the participants were female (34/50, 29/50, $35 / 50$ in milk, cheese and yogurt sessions, respectively). Participants were not given any information about the nutritional values/contents of the products. Evaluations were performed at controlled comfortable room temperature.

\section{Products}

Products were purchased from local supermarkets in Istanbul, Turkey and served at room temperature. Three types of milk (calcium \& vitamin fortified milk (FM), soy milk, and whole milk), three types of yogurt (probiotic yogurt (PY), strawberry flavoured probiotic yogurt, and plain yogurt) and four types of cream cheese (calcium, phosphate \& vitamin fortified cream cheese (FC), reduced fat cream cheese, light cream cheese, and regular cream cheese) were used in this study. Products were presented to the participants in 3-digit random number codes. Fifty ml of UHT milk samples were served in plastic transparent cups, cheese samples (12.5 g each) were served in plastic plates with plastic forks, whereas yogurt samples $(50 \mathrm{~g}$ each) were served in plastic plates with plastic spoons.

\section{Free Listing Analysis}

In a free listing analysis, consumers use their own terms to describe the samples instead of using a list of terms. Free listing sessions were performed before and after tasting the functional products (calcium \& vitamin fortified milk (FM), probiotic yogurt (PY), and calcium, phosphate \& vitamin fortified cream cheese (FC)). In the pretasting session, the participants were given the evaluation sheets and were asked to write down 4 words/phrases that came to their mind when they thought of the aforementioned products. Then, the products were served. The participants were asked to taste the samples and to fill in the evaluation sheets again with 4 words/phrases they thought of after tasting the product. Each product (FM, PY, FC) was evaluated at different days with a different group of participants (overall 116 different participants). Terms with similar meanings were grouped into the same category. Categories mentioned by equal or more than $10 \%$ of the consumers were considered as frequent terms.

\section{Check-All-That-Apply (CATA) Questions}

Check-all-that-apply (CATA) questions are multiple choice questions consisted of a list of words or phrases that could be related to the sensory characteristics of the products. This is one of the most used techniques to get information about consumers' perception of the sensory attributes of a product (Jaeger et al., 2014). One important aspect in CATA questionnaires is the generation of descriptive words because it affects the outcome of the survey (Ares et al., 2010c). For this reason, an online survey was first conducted with 60 consumers so they got to describe 'milk', 'yogurt' and 'cream cheese' by their own four words. The frequent words collected in this survey were then included in the CATA questionnaires additional to the descriptive terms collected from the literature.

Participants tasted and evaluated three types of milk, three types of yogurt, and four types of cream cheese products separately. The answers given to CATA questions about the sensory attributes of the products were analyzed using Principal Component Analysis (PCA) of XLSTAT Statistical Software for Excel (2015.2.01.17315). Moreover, Yes/No and open-ended questions were asked regarding the participants' overall preference and perception of health claims.

\section{Results and Discussion}

\section{Analysis of Milk Products}

Free listing analysis of calcium \& vitamin fortified light milk (FM): Before tasting FM, seven frequent terms were identified by the participants, all of which were healthrelated (six terms were in a positive direction and one term was in a negative direction (processed product)). The two most frequent terms (overall, $\mathrm{n}=50$ ) were "healthy" $(80 \%)$ and "nutritious" (72\%). After tasting the product, eleven frequent terms were mentioned. However, this time only three of them were health-related (healthy, nutritious, beneficial for bones and teeth) whereas the rest was related to sensory attributes. The two most frequent terms (overall, $\mathrm{n}=50)$ were "healthy" $(80 \%)$ and "sweet taste" (64\%). Moreover, the number each health-related term mentioned by the participants decreased after tasting the product except for the term 'healthy'. The cluster analysis is given 
in Table1. In both clusters, sensory-related terms became more important than health-related terms after the tasting sessions. This result suggests that taste remains a very important parameter even with functional foods.

CATA analysis and overall preferences for milk products: All participants $(100 \%)$ considered milk as a 'healthy product'. A PCA was performed on the tasting data of 50 untrained consumers (Figure 1). Two principal components (PCs) were accounted for $81 \%$ and $19 \%$ of the variance of the experimental data, respectively (Figure 1). The first PC was positively correlated to 'natural smell', 'natural taste' and 'homogenous texture'; and negatively correlated to 'high after taste' and 'sweet smell'. The second PC was positively correlated to 'medium fat content', 'tasty', 'sweet taste' and 'natural color', and negatively correlated to 'cardboard-like smell', 'offflavor', 'off note' and 'very dark color'. Sample 1 was associated with positive scores of PC1, which corresponds to a more natural perception (natural taste, natural smell and homogenous). This was expected since the first sample was whole fat cow milk. Sample 2 (fortified milk) was associated with the positive scores of PC2 and correlated with natural descriptive words. Majority of the participants found fortified milk natural in color with homogenous texture. The perception of fat content was also found similar to that of whole milk. However, the smell of fortified milk was found less natural $(40 \%)$ than the smell of whole milk $(76 \%)$ with the taste being described as sweet $(76 \%)$. Only $22 \%$ preferred fortified milk to whole fat milk, with $24 \%$ of the participants willing to buy the fortified product if there is a proven health benefit and 34\% said that they would not buy it all. On the other hand, no one preferred soymilk. Soymilk (Sample 3) was associated with the negative scores of PC2. It was found to have a very dark color, which was reported as 'unpleasant' by $98 \%$ of the participants. The smell of soymilk was described as off note $(34 \%)$ and like cardboard $(24 \%)$. The taste was associated with off flavors (42\%). This result is not very surprising since cow milk is the most commonly consumed milk in Turkey, and the consumers are not familiar with the sensory notes of soymilk. When we evaluated the liking and buying intention of the participants towards FM and soymilk, the findings confirmed the importance of smell and taste for functional foods. Although texture, color and fat content of FM were found similar to whole milk, the less natural smell besides its sweet taste was not liked by the participants, subsequently affecting their purchasing decision. Similarly, participants found the sensory properties of soymilk unfamiliar and not a single participant preferred to buy the product even if there is a proven health benefit. Moreover, it is also known that the inherent distinct beany flavor and yellow color of soymilk are affected negatively after UHT process (Lozano et al., 2007). This might be another reason why the product is even less appealing to the consumers.

\section{Analysis of Yogurt Products}

Free listing analysis of probiotic yogurt $(P Y)$ :

Before tasting PY, six frequent terms (one in negative direction: unpleasant taste) were used and five of which (all in positive direction) were health related. The most two frequent terms before tasting (overall, $n=50$ ) were "healthy" (76\%) and "good for digestion" (54\%). After tasting the product, nine frequent terms were listed. However, only three of them were health-related and the rest was about sensory attributes. The two most frequent terms after tasting (overall) were "healthy" (48\%) and "good for digestion" (36\%). The cluster analysis is given in Table 2. Similar to the free listing results of the fortified milk, more sensory related terms were pronounced in both clusters after the tasting sessions. However, different from the milk results, after tasting two health-related terms remained the most frequent.

Table 1 Free listing analysis of calcium and vitamin fortified light milk. Clusters: (1) participants from the Food Engineering Department of Yeditepe University (students and faculty members), (2) general consumer.

Department of Food Engineering members (25 participants)

\begin{tabular}{ll|ll}
\hline \multicolumn{1}{c|}{ Before Tasting* } & \multicolumn{2}{c}{ After Tasting* } \\
\hline Healthy & $96 \%$ & Healthy & $68 \%$ \\
Nutritious & $96 \%$ & Sweet taste & $60 \%$ \\
Beneficial for bones and teeth & $56 \%$ & Nutritious & $44 \%$ \\
Beneficial for children and elderly & $40 \%$ & Tasty & $36 \%$ \\
Processed product & $36 \%$ & Beneficial for bones and teeth & $28 \%$ \\
Natural & $12 \%$ & Light colour & $28 \%$ \\
& & Natural & $24 \%$ \\
& & Intense aroma & $24 \%$ \\
& & Can be preferred & $24 \%$ \\
& & Off flavour & $20 \%$ \\
\hline
\end{tabular}

\begin{tabular}{ll|ll}
\hline \multicolumn{3}{c}{ General consumer (25 participants) } \\
\hline \multicolumn{1}{c|}{ Before Tasting* } & \multicolumn{2}{c}{ After Tasting* } \\
\hline Healthy & $64 \%$ & Healthy & $92 \%$ \\
Nutritious & $48 \%$ & Sweet taste & $68 \%$ \\
Beneficial for bones and teeth & $44 \%$ & Off flavour & $36 \%$ \\
High in vitamin and mineral & $12 \%$ & Natural & $32 \%$ \\
& & Tasty & $28 \%$ \\
& & Nutritious & $24 \%$ \\
& & Light colour & $16 \%$ \\
& & Beneficial for bones and teeth & $16 \%$ \\
\hline
\end{tabular}

\footnotetext{
* Terms mentioned by equal or more than $10 \%$ of the total number of participants $(\mathrm{n}=50)$ are listed.
} 
Table 2 Free listing analysis of probiotic yogurt. Clusters: (1) participants from the Food Engineering Department of Yeditepe University (students and faculty members), (2) general consumer.

\begin{tabular}{|c|c|c|c|}
\hline \multicolumn{4}{|c|}{ Department of Food Engineering members (25 participants) } \\
\hline \multicolumn{2}{|c|}{ Before Tasting* } & \multicolumn{2}{|l|}{ After Tasting* } \\
\hline Healthy & $84 \%$ & Healthy & $60 \%$ \\
\hline Good for digestion & $60 \%$ & Good for digestion & $36 \%$ \\
\hline Intestinal protection & $52 \%$ & Tasty & $32 \%$ \\
\hline Boost immune system & $24 \%$ & Similar texture with plain yogurt & $28 \%$ \\
\hline Unpleasant taste & $16 \%$ & Can be preferred & $20 \%$ \\
\hline \multirow{2}{*}{ Nutritious } & $12 \%$ & Unfamiliar aroma & $20 \%$ \\
\hline & & Nonsweet & $16 \%$ \\
\hline \multicolumn{4}{|c|}{ General consumer (25 participants) } \\
\hline \multicolumn{2}{|c|}{ Before Tasting* } & \multicolumn{2}{|c|}{ After Tasting* } \\
\hline Healthy & $68 \%$ & Healthy & $36 \%$ \\
\hline Intestinal protection & $52 \%$ & Good for digestion & $28 \%$ \\
\hline Good for digestion & $48 \%$ & Intestinal protection & $28 \%$ \\
\hline Nutritious & $20 \%$ & Unpleasant taste & $24 \%$ \\
\hline \multirow[t]{3}{*}{ Boost immune system } & $16 \%$ & Tasty & $20 \%$ \\
\hline & & Can be preferred & $20 \%$ \\
\hline & & Similar texture with plain yogurt & $20 \%$ \\
\hline
\end{tabular}

* Terms mentioned by equal or more than $10 \%$ of the total number of participants $(n=50)$ are listed.

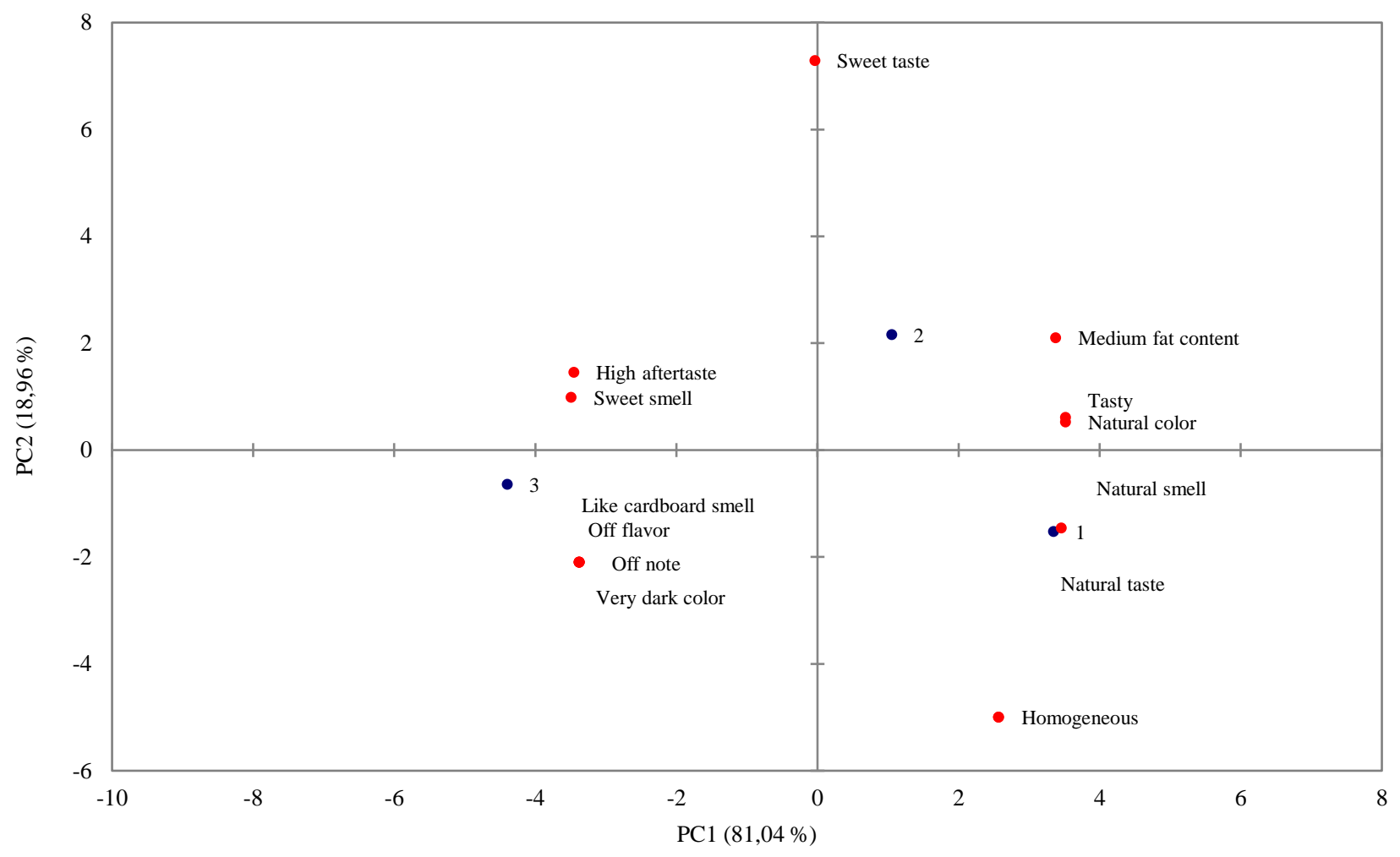

Figure 1 Biplot representation of principal component analysis (PCA) of milk products: 1. whole fat milk, 2. fortified milk, 3. soymilk

CATA analysis and overall preferences for yogurt products: All participants $(100 \%)$ considered yogurt as a 'healthy product'. A PCA was performed on the tasting data of 50 untrained consumers (Figure 2). The first PC was positively correlated to 'natural smell', 'natural color' and 'milky smell' and negatively correlated to 'high sugar' and 'creamy'. The second PC was positively correlated to 'high mouthfeel', 'soft texture', 'nonsugary' and 'natural taste', and negatively correlated to 'sweet taste', 'viscous texture', 'tasty' and 'medium fat content'. Sample 1 was associated with positive scores of PC1, corresponding to a more natural perception (natural color, natural smell, and milky smell). This result was expected since the first sample was plain yogurt, which is the most consumed yogurt product in Turkey. Sample 2 (probiotic yogurt) was associated with the positive scores of PC2 and correlated with positive texture and taste descriptions. Sample 3 (strawberry probiotic yogurt) was associated with negative scores of PC1 and PC2. However, the texture of the strawberry probiotic yogurt was found to be the smoothest $(50 \%)$. Forty eight percent of the participants found strawberry probiotic yogurt high in sugar. On the other 
hand, $50 \%$ of the participants found probiotic yogurt nonsweet, whereas $42 \%$ were pleased with its low sugar content. The taste of the probiotic yogurt was described as natural $(48 \%)$ and high mouthfeel (38\%), while the taste of strawberry flavored probiotic yogurt was described as sweet $(84 \%)$, tasty $(62 \%)$ and creamy $(42 \%)$.

Only $26 \%$ of the participants declared the willingness to buy probiotic products if there is a proven health benefit, whereas $34 \%$ said that they would not buy it at all. On the other hand, given that they already consume the probiotic yogurt, $54 \%$ of the participants indicated that they would consume it only if it is flavored. This result shows that although probiotic yogurt was found similar to plain yogurt while being associated with natural components; the sweet taste together with creamy texture influenced the purchasing intent of the consumer. Thus, they preferred flavored probiotic yogurt to plain probiotic yogurt. ContiSilva and de Souza-Borges (2019) also reported that intrinsic sensory characteristics are very important for the overall liking of commercial probiotic fermented milk products. Moreover, another study showed that even with calorie-reduced yogurt, 'taste' was a very important motive for the purchasing (Johansen et al., 2011).

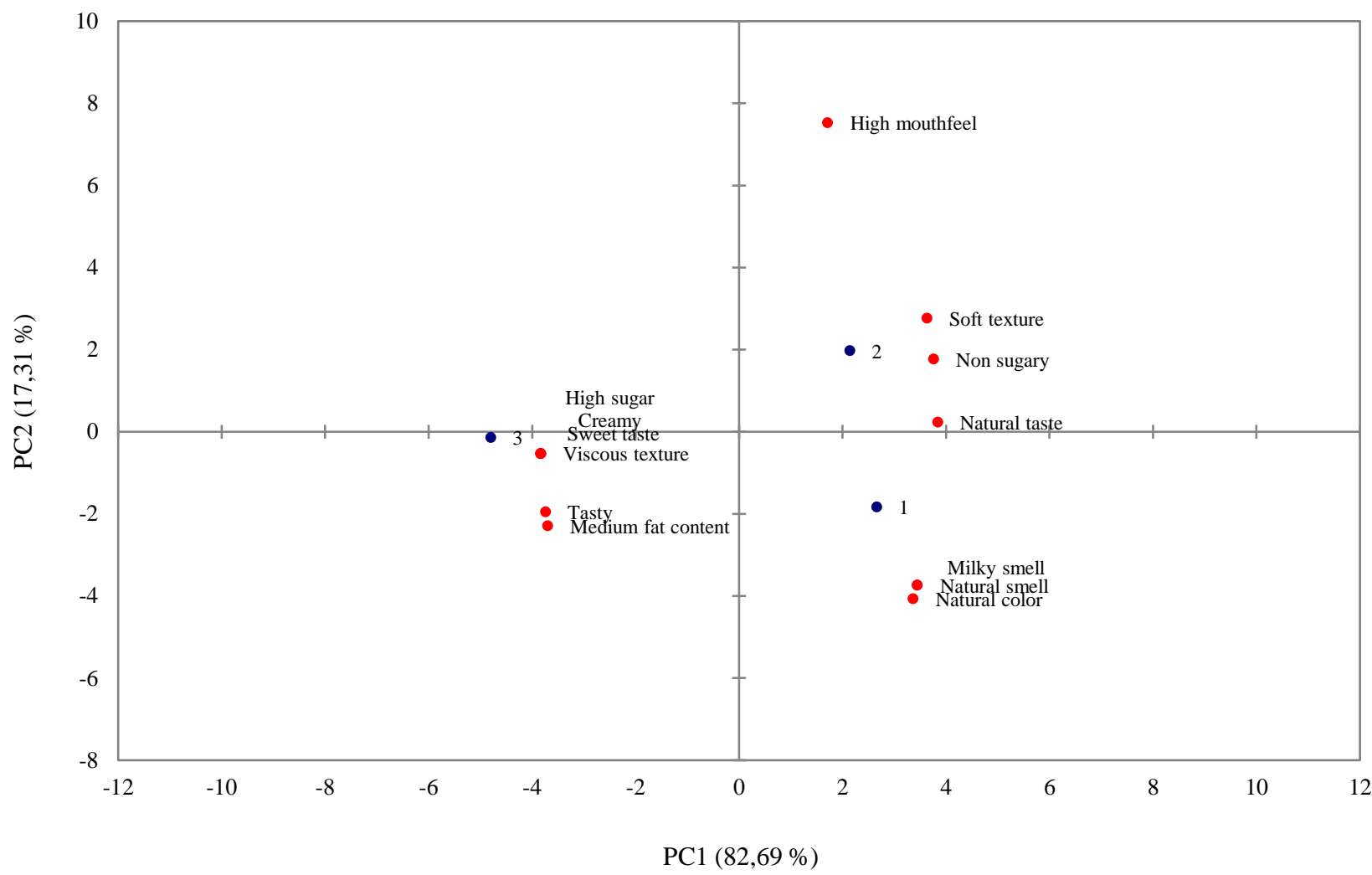

Figure 2 Biplot represantation of principal component analysis (PCA) of yogurt products: 1. plain yogurt, 2. probiotic yogurt, 3 . strawberry flavored probiotic yogurt

\section{Analysis of Cream Cheese Products}

Free listing analysis of calcium, phosphate, and vitamin fortified cream cheese $(F C)$ : Before tasting FC, seven frequent terms were used and five of which were health-related (one in negative direction). The most frequent terms before tasting were "nutritious" (56\%), "beneficial for bones \& teeth" (44\%) and "healthy" (44\%). After tasting the product, eleven frequent terms were listed. However, only two of them were health-related and the rest was about sensory and fat content. The two most frequent terms were "healthy" (44\%) and "unpleasant taste" (36\%). The cluster analysis is given in Table 3. A dramatic decrease in health-related terms in both clusters after tasting once again indicates the importance of sensory properties regardless of health awareness and education of the consumer.

CATA analysis and overall preferences for cream cheese products: All participants (100\%) considered cheese as a 'healthy product'. A PCA was performed on the tasting data of 50 untrained consumers (Figure 3 ). The first PC was positively correlated to 'natural smell', 'natural color', 'medium fat' and 'high mouthfeel', 'light color' and negatively correlated to 'dark color', 'high fat content' and 'high after taste'. The second PC was positively correlated to 'buttery', 'milky smell' and 'soft', and negatively correlated to 'firm', and 'low mouthfeel'. Whole fat cream cheese (sample 1) was associated with negative scores of PC1. On the other hand, reduced fat cream cheese (sample 2) was associated with positive scores of PC1 that correspond to a more natural perception. Light cream cheese (sample 3) was found to be similar to reduced fat cream cheese. Sample 4 (fortified cheese) was associated with negative scores of PC2. Participants found fortified cheese dark in color with low mouthfeel. The smell of FC was found natural by $38 \%$ of the participants, which was lower than the number of participants who found reduced $(56 \%)$ and light $(52 \%)$ cream cheese samples natural in the smell. The fortified cream cheese 
was described as less buttery than the other three. Only $14 \%$ of the participants declared the willingness to buy fortified cream cheese if there is a proven health benefit, whereas $32 \%$ mentioned that they would not buy it at all. The participants preferring reduced fat cream cheese and light cream cheese added up to $68 \%$, while only $18 \%$ of them preferred whole fat cream cheese. This result shows that consumers have a tendency towards medium fat content but high mouthfeel for cream cheese products, and they also look for natural color and smell. Earlier studies also showed that the fat content of cheese is important for the purchasing motive in two ways, either it is related to the taste that will increase the enjoyment during consumption, or it can be related to the healthiness thus a better physical condition (Grunert et al., 2000; Johansen et al., 2011). Moreover, consumers prefer a low-fat cream cheese product to a fortified cream cheese product with more health benefits, since the latter lacks good sensory attributes.

Table 3 Free listing analysis of calcium, phosphate and vitamin fortified cream cheese. Clusters: (1) participants from the Food Engineering Department of Yeditepe University (students and faculty members), (2) general consumer.

Department of Food Engineering members (25 participants)

\begin{tabular}{|c|c|c|c|}
\hline \multicolumn{2}{|c|}{ Before Tasting* } & \multicolumn{2}{|c|}{ After Tasting* } \\
\hline Nutritious & $88 \%$ & Healthy & $48 \%$ \\
\hline Healthy & $52 \%$ & Low intense taste & $40 \%$ \\
\hline Beneficial for bones and teeth & $52 \%$ & Dark colour & $36 \%$ \\
\hline Beneficial for children & $16 \%$ & High fat content & $32 \%$ \\
\hline \multirow[t]{3}{*}{ High in additives } & $12 \%$ & Tasty & $20 \%$ \\
\hline & & Non-fat & $20 \%$ \\
\hline & & Unpleasant taste & $12 \%$ \\
\hline \multicolumn{4}{|c|}{ General consumer (25 participants) } \\
\hline \multicolumn{2}{|c|}{ Before Tasting* } & \multicolumn{2}{|c|}{ After Tasting* } \\
\hline Good for breakfast & $64 \%$ & Healthy & $40 \%$ \\
\hline Healthy & $36 \%$ & Dark colour & $36 \%$ \\
\hline Beneficial for bones & $36 \%$ & Low intense taste & $28 \%$ \\
\hline Nutritious & $24 \%$ & Beneficial for bones & $28 \%$ \\
\hline \multirow[t]{3}{*}{ Made of milk } & $16 \%$ & Tasty & $24 \%$ \\
\hline & & Non-fat & $20 \%$ \\
\hline & & Hard texture & $20 \%$ \\
\hline
\end{tabular}

* Terms mentioned by equal or more than $10 \%$ of the total number of participants $(\mathrm{n}=50)$ are listed

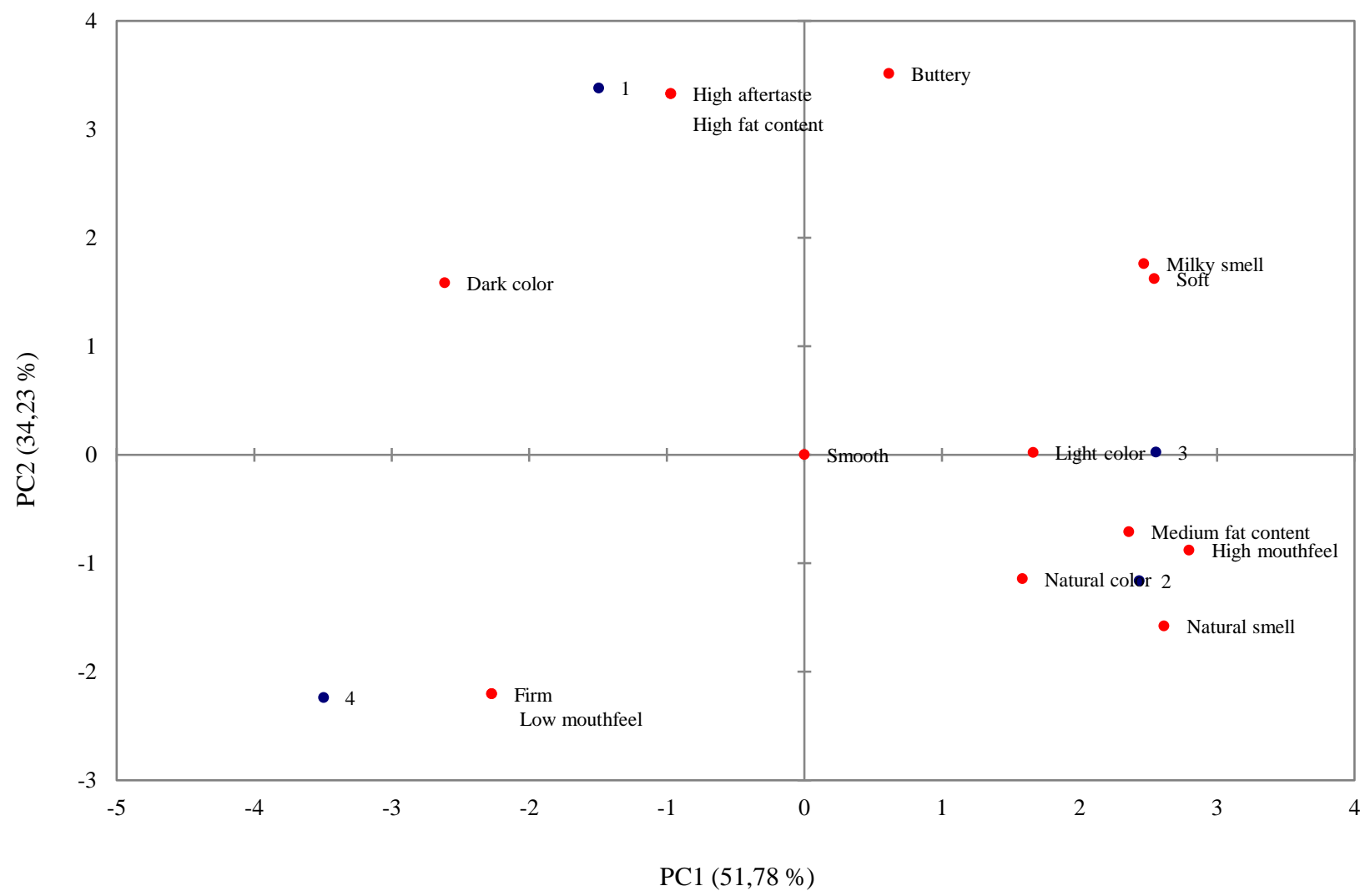

Figure 3 Principal Component Analysis (PCA) of cream cheese products: 1. whole fat cream cheese, 2. reduced fat cream cheese, 3 . light cream cheese, 4 . fortified cream cheese 


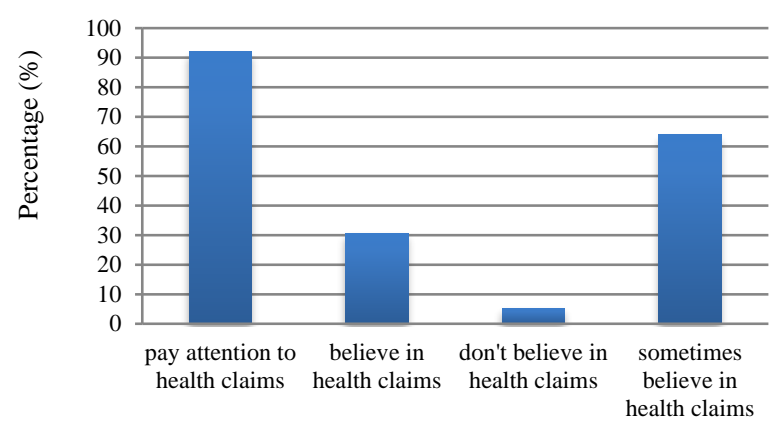

Figure 4 Consumer perception on the health claims declared on the packages

Consumer Perception of Health Claims on The Labels

Health claims on the package were reported to help the consumers in the purchasing process of functional foods by providing the information for the food choices (Leathwood et al., 2007; Williams, 2005). The participants' interest and trust in the health claims on the food packages in our study are given in Figure 4. Although $92 \%$ of our participants paid attention to the health claims on the packages, only 30 $\%$ believed in the benefits written on the packages.

In the overall study, the participants who were inclined to buy functional products also answered an open-ended question about what claim would make them buy those products. In order to buy a product with health benefits, $37 \%$ of the participants expected to see a certified claim on the label; $16 \%$ of the participants looked for detailed information about the ingredients and higher nutritional values, and $4 \%$ of the participants expect the product to be one hundred percent natural. These findings are in agreement with previous works which showed that when claims effectively describe the nutritional properties and health benefits, especially when verified by a government agency rather than the producer, consumers' tendency for purchasing is affected positively (Van Kleef et al., 2005; Williams, 2005, Siegrist et al., 2008; Hailu et al., 2009; Aschemann-Witzel et al., 2013). Many studies conducted worldwide (Kaur and Singh, 2017) show that people generally don't trust the information on the labels; thus, providing accredited information on the labels is necessary to overcome the lack of confidence of the consumers and to increase the perceived value of the functional food product.

\section{Conclusion}

Dairy products are usually perceived as healthy choices by the consumer in the product's conventional form, yet there are also a good number of functional dairy products in the market. We studied Turkish consumers' perception of functional dairy products in three different categories and their purchasing intentions. In the free listing analysis, the number of frequent terms related to health dramatically decreased after tasting session for all products, whereas sensory related terms became more important. This result suggests that taste is a very important parameter even with the healthy products. CATA analysis showed that consumers look for different product properties in different dairy categories. For example, in milk consumers prefer the natural smell and natural taste and, for this reason, they did not enjoy fortified milk and soymilk, since the taste and smell of these products were not similar to the familiar regular whole cow milk. On the other hand, flavored probiotic yogurt was preferred over the plain version despite its similar sensory attributes. The sweet taste and creamy texture of flavored probiotic yogurt affected the purchasing intent of the consumer. In the case of cream cheese products, low-fat cream cheese products were preferred over fortified and whole fat. This result indicates that reducing fat content while maintaining high mouthfeel and the natural taste is more attractive to the consumers rather than fortification. From the results of free listing test and CATA analysis, it can be concluded that, regardless of their education and awareness, consumers still are not willing to compromise on taste of dairy foods independent of how healthy the product is. All participants considered milk, yogurt, and cheese as healthy options in their conventional form. Their preference of functional dairy products was only $22 \%, 26 \%$ and $14 \%$ for the fortified milk, probiotic yogurt, and fortified cream cheese, respectively. Moreover, only $30 \%$ of the participants were found to believe the health claims on the package, which is another obstacle the functional food industry faces. To solve this problem, one approach might be providing accredited information on the label while educating the consumer via different strategies. In addition, verification of the claims by a government agency rather than the producer might also help to overcome the lack of consumer confidence.

\section{References}

Annunziata A, Vecchio R. 2013. Consumer perception of functional foods: A conjoint analysis with probiotics. Food Qual Prefer, 28: 348-355. DOI: 10.1016/j.foodqual.2012.10.009.

Aschemann-Witzel J, Maroscheck N, Hamm U. 2013. Are organic consumers preferring or avoiding foods with nutrition and health claims? Food Qual Prefer, 30: 68-76. DOI: 10.1016/j.foodqual.2013.04.011.

Ares G, Gámbaro A. 2007. Influence of gender, age, and motives underlying food choice on perceived healthiness and willingness to try functional foods. Appetite, 49:148-158. DOI:10.1016/j.appet.2007.01.006.

Ares G, Besio M, Giménez A, Deliz R. 2010a. The relationship between involvement and functional milk desserts intention to purchase. Influence on attitude towards packaging characteristics. Appetite, 55: 298-304. DOI: 10.1016/j.appet.2010.06.016.

Ares G, Giménez A, Deliz R. 2010b. Influence of three nonsensory factors on consumer choice of functional yogurts over regular ones. Food Qual Prefer, 21: 361-367. DOI: 10.1016/j.foodqual.2009.09.002.

Ares G, Barreiro C, Deliza R, Giménez A, Gámbaro A. 2010c. Consumer expectations and perception of chocolate milk desserts enriched with antioxidants. J Sens Stud, 25: 243-260. DOI: 10.1111/j.1745-459X.2010.00293.x.

Bimbo F, Bonanno A, Nocella G, Viscecchia R, Nardone G, De Devitiis B, Carlucci D. 2017. Consumers' acceptance and preferences for nutrition-modified and functional dairy products: A systematic review. Appetite, 113: 141-154. DOI: 10.1016/j.appet.2017.02.031.

Bornkessel S, Bröring S, Omta SWF, van Trijp H. 2014. What determines ingredient awareness of consumers? A study on ten functional food ingredients. . Food Qual Prefer, 32: 330339. DOI: 10.1016/j.foodqual.2013.09.007. 
Bower JA, Saadat MA, Whitten C. 2003. Effect of liking, information and consumer characteristics on purchase intention and willingness to pay more for a fat spread with a proven health benefit. Food Qual Prefer, 14: 65-74. DOI: 10.1016/s0950-3293(02)00019-8.

Büyükkaragöz A, Bas M, Sağlam D, Cengiz ŞE. 2014. Consumers' awareness, acceptance, and attitudes towards functional foods in Turkey. Int J Consum Stud, 36: 628-635. DOI: $10.1111 / \mathrm{ijcs} .12134$.

Carillo E, Prado-Gasco V, Fiszman S, Varela P. 2013. Why buying functional foods? Understanding spending behavior through structural equation modeling. Food Res Int, 50: 361368. DOI: 10.1016/j.foodres.2012.10.045.

Conti-Silva AC, de Souza-Borges PK. 2019. Sensory characteristics, brand and probiotic claim on the overall liking of commercial probiotic fermented milks: Which one is more relevant? Food Res Int, 116: 184-189. DOI: 10.1016/j.foodres.2018.08.011.

Coxa DN, Koster A, Russell CG. 2004. Predicting intentions to consume functional foods and supplements to offset memory loss using an adaptation of protection motivation theory. Appetite, 43: 55-64. DOI: 10.1016/j.appet.2004.02.003.

Fenko A, Lotterman H, Galetzka M. 2016. What's in a name? The effects of sound symbolism and package shape on consumer responses to food products. Food Qual Prefer, 51: 100-108. DOI: 10.1016/j.foodqual.2016.02.021.

Gulseven O, Wohlgenant M. 2014. Demand for functional and nutritional enhancements in specialty milk products. Appetite, 81:284-294. DOI: 10.1016/j.appet.2014.06.105.

Grunert KG, Bech-Larsen T, Bredahl L. 2000. The issues in consumer quality perception and acceptance of dairy products. Int Dairy J, 10: 575-584. DOI: $10.1016 /$ S09586946(00)00085-6.

Hailu G, Boecker A, Henson S, Cranfield J. 2009. Consumer valuation of functional foods and nutraceuticals in Canada. A conjoint study using probiotics. Appetite, 52: 257-265. DOI:10.1016/j.appet.2008.10.002.

Johansen SB, Næs T, Øyaas J, Hersleth M. 2010. Acceptance of calorie-reduced yoghurt: Effects of sensory characteristics and product information. Food Qual Prefer, 21: 13-21. DOI:10.1016/j.foodqual.2009.07.003.

Johansen SB, Næs T, Øyaas J, Hersleth M. 2011. Motivation for choice and healtiness perception of calorie-reduced dairy products. A cross-cultural study. Appetite, 56: 15-24. DOI: 10.1016/j.appet.2010.11.137

Jaeger SR, Cadena RS, Torres-Moreno M, Antunez L, Vidal L, Gimenez A, Hunter DC, Beresford MK, Kam K, Yin D, Paisley AG, Chheang SL, Ares G. 2014. Comparison of check-all-that-apply and forced-choice Yes/No question formats for sensory characterization. Food Qual Prefer, 35: 32-40. DOI: 10.1016/j.foodqual.2014.02.004.

Kaur N, Singh DP. 2017. Deciphering the consumer behavior facets of functional foods: A literature review. Appetite. 112:167-187. DOI: 10.1016/j.appet.2017.01.033.

Karagözlü C. 2015. Fonksiyonel süt ürünleri piyasasında tüketici eğilimleri.

https://www.sutdunyasi.com/haberler/fonksiyonel-suturunleri-piyasasinda-tuketici-egilimleri/ (12.12.2018)

Krutulyte R, Grunert KG, Scholderer J, Hagemanna KS, Elgaarda P, Nielsena B, Graverholt JP. 2008. Motivational factors for consuming omega-3 PUFAs: An exploratory study with Danish consumers.Appetite, 5:137-147. DOI: 10.1016/j.appet.2008.01.005.
Krutulyte R, Grunert KG, Scholderer J, Lähteenmäki L, Hagemann KS, Elgaard P, Nielsen B, Graverholt JP. 2011. Perceived fit of different combinations of carriers and functional ingredients and its effect on purchase intention. Food Qual Prefer, 22: 11-16. DOI: 10.1016/j.foodqual.2010.06.001.

Leathwood PD, Richardson DP, Strater P, Todd PM, van Trijp HC. 2007. Consumer understanding of nutrition and health claims: Sources of evidence. Brit J Nutr, 98: 474-484. DOI: 10.1017/S000711450778697X.

Lindeman M, Sirelius M. 2001. Food choice ideologies. The modern manifestations of normative and humanist views of the world. Appetite, 37: 175-184. DOI: 10.1016/appe.2001.0437.

Lozano PR, Darke M, Benitez D, Cadwallader KR. 2007. Instrumental and sensory characterization of heat-induced odorants in aseptically packaged soymilk. J Agric Food Chem, 55:3018-3026. DOI: 10.1021/jf0631225.

Menezes E, Deliza R, Chan HL, Guinard J-X. 2011. Preferences and attitudes towards açaí-based products among North American consumers. Food Res Int, 44:1997-2008. DOI: 10.1016/j.foodres.2011.02.048.

Nocella G, Kennedy O. 2012. Food health claims-What consumers understand. Food Policy, 37: 571-580. DOI: 10.1016/j.foodpol.2012.06.001.

Ozen AE, Pons A, Tur JA. 2012. Worldwide consumption of functional foods: A systematic review. Nutr Rev, 70: 472481. DOI: $10.1111 / j .1753-4887.2012 .00492 . x$

Özen AE, Bibiloni M, Pons A, Tur JA. 2014. Consumption of functional foods in Europe; a systematic review. Nutr Hosp, 29: 470-478. DOI: 10.3305/nh.2014.29.3.7148.

Pappalardo G., Lusk JL. 2016. The role of beliefs in purchasing process of functional foods. Food Qual Prefer, 53: 151-158. DOI: 10.1016/j.foodqual.2016.06.009.

Pinto VRA, Freitas TBO, Dantas MIS, Lucia SMD, Melo LF, Minim VPR, Bressan J. 2017. Influence of package and health-related claims on perception and sensory acceptability of snack bars. Food Res Int, 101: 103-113. DOI: 10.1016/j.foodres.2017.08.062.

Shepherd R. 1999. Social determinants of food choice. Proc Nutr Soc, 58: 807-812. DOI: 10.1017/S0029665199001093.

Siegrist M, Stampfli N, Kastenholz H. 2008. Consumers' willingness to buy functional foods. The influence of carrier, benefit and trust. Appetite, 51:526-529. DOI: 10.1016/j.appet.2008.04.003.

Siró I, Kápolna E, Kápolna B, Lugasi A. 2008. Functional food. Product development, marketing and consumer acceptance-a review. Appetite, 51: 456-467. DOI: 10.1016/j.appet.2008.05.060.

Urala N, Lähteenmäki L. 2007. Consumers' changing attitudes towards functional foods. Food Qual Prefer, 18: 1-12. DOI: 10.1016/j.foodqual.2005.06.007.

Van Kleef E, Van Trijp HCM, Luning P. 2005. Functional foods: Health claim-food product compatibility and the impact of health claim framing on consumer evaluation. Appetite, 44: 299-308. DOI: 10.1016/j.appet.2005.01.009.

Verbeke W. 2006. Functional foods: Consumer willingness to compromise on taste for health? Food Qual Prefer, 17:126131. DOI: 10.1016/j.foodqual.2005.03.003.

Williams P. 2005. Consumer understanding and use of health claims for foods. Nutr Rev, 63: 256-264. DOI: 10.1111/j.1753-4887.2005.tb00382.x 